RESEARCH BRIEF

\title{
Self-Perceived Poor/Fair Health, Frequent Mental Distress, and Health Insurance Status Among Working-Aged US Adults
}

\author{
Guixiang Zhao, MD, $\mathrm{PhD}^{1}$; Catherine A. Okoro ${ }^{1}$; Jason Hsia ${ }^{1}$; Machell Town ${ }^{1}$
}

\begin{abstract}
Accessible Version: www.cdc.gov/pcd/issues/2018/17_0523.htm
Suggested citation for this article: Zhao G, Okoro CA, Hsia J, Town M. Self-Perceived Poor/Fair Health, Frequent Mental Distress, and Health Insurance Status Among Working-Aged US Adults. Prev Chronic Dis 2018;15:170523. DOI: https://doi.org/ 10.5888/pcd15.170523.
\end{abstract}

\section{PEER REVIEWED}

\section{Abstract}

We examined associations of health insurance status with self-perceived poor/fair health and frequent mental distress (FMD) among working-aged US adults from 42 states and the District of Columbia using data from the 2014 Behavioral Risk Factor Surveillance System. After multiple-variable adjustment, compared with adequately insured adults, underinsured and never insured adults were $39 \%$ and $59 \%$ more likely to report poor/fair health, respectively, and 38\% more likely to report FMD. Compared with working-aged adults with employer-based insurance, adults with Medicaid/Medicare or other public insurance coverage were $28 \%$ and $13 \%$ more likely to report poor/fair health, respectively, and $15 \%$ more likely to report FMD. Increasing insurance coverage and reducing cost barriers to care may improve general and mental health.

\section{Objective}

Self-rated health and health-related quality of life (HRQOL) are commonly used measures of overall well-being, physical health conditions, and functioning $(1,2)$ and are key indicators for assessing national health in Healthy People objectives. Socioeconomic status, lifestyle factors, and chronic conditions affect self-rated health and HRQOL $(3,4)$.

Health insurance improves access to and affordability of care, which can be critical to managing chronic conditions; lacking ad- equate coverage and not being able to afford care can cause mental distress $(5,6)$. We examined associations of health insurance coverage and type of coverage with self-perceived poor/fair health and frequent mental distress (FMD) among working-aged US adults.

\section{Methods}

The Behavioral Risk Factor Surveillance System (BRFSS) is a state-based, landline-telephone and cellular-telephone survey of noninstitutionalized civilian US adults (7). In 2014, 42 states and the District of Columbia collected health care access data through both core and module questions, which were used for this analysis. The BRFSS protocol was approved by the Centers for Disease Control and Prevention institutional review board. The median response rate was $47.0 \%$ in 2014 .

Survey participants' self-perceived health was dichotomized into poor/fair and good/very good/excellent. FMD was defined as having 14 or more days of poor mental health (including stress, depression, and problems with emotions) in the past 30 days.

The survey questions and categorization of participants' insurance status and type of insurance are described elsewhere (8). Health insurance coverage over the past 12 months was categorized as adequately insured, underinsured, and never insured. Type of coverage was categorized as employer-based, self-purchased, Medicaid or Medicare; other public or some other source, and not currently insured.

Study covariates were age, sex, race/ethnicity, education level, marital status, employment status, federal poverty level (FPL), current smoking, leisure-time physical activity, body mass index, and the number of chronic conditions/diseases including diabetes, coronary heart disease, stroke, current asthma, arthritis, cancer, chronic obstructive pulmonary disease, history of depression, kidney disease, and disability. 
Participants who responded "don't know/not sure," refused to answer, or had missing responses to any study covariates mentioned above were excluded, leaving 201,781 working-aged adults (aged 18-64 years) in the analytic sample. After further excluding participants with missing data on the 2 outcome variables, 201,423 participants remained for the analysis for self-rated poor/fair health and 199,709 participants remained for the analysis for FMD.

We estimated the weighted prevalence for self-perceived poor/fair health and FMD by health insurance coverage and type of coverage. Log-linear regression analyses were conducted to estimate adjusted prevalence ratios with $95 \%$ confidence intervals (CIs) while controlling for study covariates. SAS-callable SUDAAN (Research Triangle Institute) was used to account for the complex survey design. Significance was set at $P<.05$.

\section{Results}

Of 201,781 working-aged adults, the mean age was 41 years; $49.0 \%$ were women; $69.9 \%$ were non-Hispanic white; $13.5 \%$ were non-Hispanic black; and 9.8\% were Hispanic. Approximately $59.9 \%$ had a degree higher than high school; $14.8 \%$ lived below the poverty level (ie, household income $<100 \%$ of FPL); $20.6 \%$ were current smokers; $20.6 \%$ were physically inactive; $29.8 \%$ were obese; and $48.6 \%$ had at least 1 chronic condition or disability.

For insurance status, $57.3 \%$ were adequately insured, $32.3 \%$ underinsured, and 10.4\% never insured. Approximately $56.2 \%$ had employer-based coverage; $9.5 \%$ had self-purchased coverage; $13.8 \%$ had Medicaid or Medicare; $5.3 \%$ had other public insurance; and $15.2 \%$ were not currently insured.

Overall, $14.8 \%$ (95\% CI, 14.6\%-15.1\%) of adults reported poor/ fair health, and $12.5 \%(95 \% \mathrm{CI}, 12.2 \%-12.7 \%)$ reported FMD (Table 1). Prevalence differed by sociodemographic characteristics, lifestyle risk factors, and number of chronic conditions and disability.

The age-adjusted prevalence of poor/fair health and FMD was significantly higher among underinsured adults $(21.8 \%$ and $18.8 \%$, respectively) and never insured adults $(23.4 \%$ and $16.8 \%$, respectively) compared with adequately insured adults $(8.9 \%$ and $8.5 \%$, respectively) (Table 2 ). The age-adjusted prevalence of poor/fair health and FMD were lowest among adults with employer-based insurance $(7.8 \%$ and $8.5 \%$, respectively) or self-purchased coverage $(9.3 \%$ and $8.8 \%$, respectively) and highest among adults with Medicaid/Medicare (36.5\% and 27.2\%, respectively).

After multiple-variable adjustment for study covariates, compared with adequately insured adults, underinsured and never insured adults were 39\% $(P<.001)$ and 59\% $(P<.001)$, respectively, more likely to report poor/fair health, and 38\% $(P<.001$ for both) more likely to report FMD (Table 2). Compared with adults with employer-based insurance, those with Medicaid/Medicare or other public coverage were more likely to report poor/fair health $(28 \%$ and $13 \%$, respectively, $P<.001)$ and FMD $(15 \%$ for both, $P<$ $.001)$.

\section{Discussion}

Self-assessed health status reflects concurrent decrements in health associated with physical functional status and certain chronic illnesses (1), and lower self-rated health predicts increased mortality $(2,9)$. Poor mental health is associated with risky health behaviors and social burden $(6,10)$. Our results from a large population survey demonstrated that self-perceived health and FMD were significantly associated with health insurance status, independent of socioeconomic status; behavioral risk factors; and multiple chronic conditions and disability. Working-aged adults who were underinsured and never insured or who had Medicaid/Medicare or other public insurance were more likely to rate their general health as poor/fair and to report FMD than their counterparts who were adequately insured or had private insurance.

Research indicates that having insurance coverage predicts better self-rated health $(3,11,12)$ and that prevalence of FMD is significantly higher among adults with no health insurance coverage $(5,6)$ or with financial barriers to needed medical care (5). These results are consistent with our findings that the prevalence of poor/fair health and FMD were significantly higher among underinsured and uninsured adults. Moreover, our results further demonstrated that poor/fair health and FMD were significantly higher among adults with Medicaid/Medicare or other public insurance than among those with private coverage, either employer-based or selfpurchased. Adults younger than 65 years who have Medicare or Medicaid are likely to have permanent disabilities or certain terminal diseases, or live in poverty; all of these may contribute to a higher prevalence of poor/fair health or FMD.

The strength of our study is that results are based on a large population surveillance system. BRFSS data, however, are self-reported and subject to recall bias. Also, because BRFSS excluded institutionalized adults, prevalence of poor/fair health and FMD may be underestimated. In addition, data were from 42 states and the District of Columbia, which limits generalizability of the study results to the entire US working-aged population.

Although uninsurance rates are declining in the United States (13), the trend in the rates of being underinsured or having private cov-

\footnotetext{
The opinions expressed by authors contributing to this journal do not necessarily reflect the opinions of the U.S. Department of Health and Human Services, the Public Health Service, the Centers for Disease Control and Prevention, or the authors' affiliated institutions.
} 
erage are largely unknown. Continuing efforts to increase health insurance coverage and reduce cost barriers to needed medical care may help the US population achieve optimal overall health and reduce mental distress.

\section{Acknowledgments}

The authors thank the BRFSS coordinators from state health departments for their participation in data collection. There was no financial support associated with this study. There were no copyrighted materials or copyrighted surveys/instruments/tools used in this study. The findings and conclusions in this report are those of the authors and do not necessarily represent the official position of the Centers for Disease Control and Prevention.

\section{Author Information}

Corresponding Author: Guixiang Zhao, MD, PhD, Division of Population Health, Centers for Disease Control and Prevention, 4770 Buford Hwy, MS F-78, Atlanta, GA 30341. Telephone: 770-488-4450. Email: fwj4@cdc.gov.

Author Affiliations: ${ }^{1}$ Division of Population Health, National Center for Chronic Disease Prevention and Health Promotion, Centers for Disease Control and Prevention, Atlanta, Georgia.

\section{References}

1. Gold M, Franks P, Erickson P. Assessing the health of the nation. The predictive validity of a preference-based measure and self-rated health. Med Care 1996;34(2):163-77.

2. Franks P, Gold MR, Fiscella K. Sociodemographics, self-rated health, and mortality in the US. Soc Sci Med 2003; 56(12):2505-14.

3. Kim J. Socioeconomic inequalities in self-rated health among middle-aged and older adults. Soc Work Health Care 2011; 50(2):124-42.

4. Tsai J, Ford ES, Li C, Zhao G, Pearson WS, Balluz LS. Multiple healthy behaviors and optimal self-rated health: findings from the 2007 Behavioral Risk Factor Surveillance System Survey. Prev Med 2010;51(3-4):268-74.

5. Bruning J, Arif AA, Rohrer JE. Medical cost and frequent mental distress among the non-elderly US adult population. $J$ Public Health (Oxf) 2014;36(1):134-9.

6. Pearson WS, Dhingra SS, Strine TW, Liang YW, Berry JT, Mokdad AH. Relationships between serious psychological distress and the use of health services in the United States: findings from the Behavioral Risk Factor Surveillance System. Int J Public Health 2009;54(S1,Suppl 1):23-9.
7. Centers for Disease Control and Prevention. Behavioral Risk Factor Surveillance System. https:/www.cdc.gov/brfss/2017.

8. Zhao G, Okoro CA, Li J, Town M. Health insurance status and clinical cancer screenings among US Adults. Am J Prev Med 2017;54(1):11-19.

9. Regidor E, Guallar-Castillón P, Gutiérrez-Fisac JL, Banegas JR, Rodríguez-Artalejo F. Socioeconomic variation in the magnitude of the association between self-rated health and mortality. Ann Epidemiol 2010;20(5):395-400.

10. Strine TW, Balluz L, Chapman DP, Moriarty DG, Owens M, Mokdad AH. Risk behaviors and healthcare coverage among adults by frequent mental distress status, 2001. Am J Prev Med 2004;26(3):213-6.

11. Alexopoulos EC, Geitona M. Self-rated health: inequalities and potential determinants. Int J Environ Res Public Health 2009; 6(9):2456-69.

12. Franks P, Clancy CM, Gold MR, Nutting PA. Health insurance and subjective health status: data from the 1987 National Medical Expenditure survey. Am J Public Health 1993; 83(9):1295-9.

13. Zhao G, Okoro CA, Dhingra SS, Xu F, Zack M. Trends of lack of health insurance among US adults aged 18-64 years: findings from the Behavioral Risk Factor Surveillance System, 1993-2014. Public Health 2017;146:108-17.

The opinions expressed by authors contributing to this journal do not necessarily reflect the opinions of the U.S. Department of Health and Human Services, the Public Health Service, the Centers for Disease Control and Prevention, or the authors' affiliated institutions. 


\section{Tables}

Table 1. Crude Prevalence of Self-Perceived Poor/Fair Health and FMD Among Working-Aged Adults in 42 States and the District of Columbia, by Sociodemographic Characteristics, Health-Related Behaviors, and Chronic Conditions and Disability, Behavioral Risk Factor Surveillance System, 2014

\begin{tabular}{|c|c|c|c|c|}
\hline \multirow[b]{2}{*}{ Characteristic } & \multicolumn{2}{|c|}{ Poor/Fair Health } & \multicolumn{2}{|c|}{ FMD } \\
\hline & No. & $\%(95 \% \mathrm{Cl})$ & No. & $\%(95 \% \mathrm{Cl})$ \\
\hline Overall & 201,423 & $14.8(14.6-15.1)$ & 199,709 & $12.5(12.2-12.7)$ \\
\hline \multicolumn{5}{|l|}{ Age, $y$} \\
\hline $18-25$ & 17,710 & $8.1(7.5-8.8)$ & 17,580 & $13.1(12.3-13.9)$ \\
\hline $26-44$ & 61,137 & $12.3(11.9-12.8)$ & 60,708 & $12.6(12.1-13.0)$ \\
\hline $45-64$ & 122,576 & $19.9(19.5-20.3)$ & 121,421 & $12.1(11.8-12.4)$ \\
\hline \multicolumn{5}{|l|}{ Sex } \\
\hline Male & 89,898 & $14.2(13.8-14.6)$ & 89,154 & $10.2(9.8-10.6)$ \\
\hline Female & 111,525 & $15.6(15.2-15.9)$ & 110,555 & $14.8(14.4-15.2)$ \\
\hline \multicolumn{5}{|l|}{ Race/ethnicity } \\
\hline Non-Hispanic white & 158,790 & $13.0(12.8-13.3)$ & 157,563 & $12.3(12.0-12.6)$ \\
\hline Non-Hispanic black & 18,678 & $19.3(18.4-20.2)$ & 18,494 & $13.8(13.0-14.7)$ \\
\hline Hispanic & 12,595 & $22.6(21.4-23.9)$ & 12,450 & $12.4(11.5-13.4)$ \\
\hline Other & 11,360 & $13.4(12.3-14.5)$ & 11,202 & $11.2(10.3-12.2)$ \\
\hline \multicolumn{5}{|l|}{ Education level } \\
\hline$<$ High school graduate & 12,210 & $34.2(32.9-35.6)$ & 11,943 & $21.3(20.1-22.5)$ \\
\hline High school graduate/GED & 53,224 & $18.1(17.6-18.6)$ & 52,602 & $13.9(13.4-14.4)$ \\
\hline >High school graduate & 135,989 & $9.6(9.3-9.8)$ & 135,164 & $10.1(9.8-10.4)$ \\
\hline \multicolumn{5}{|l|}{ Marital status } \\
\hline Married & 115,424 & $11.9(11.6-12.2)$ & 114,687 & $8.9(8.6-9.2)$ \\
\hline Previously married & 39,528 & $26.3(25.6-27.1)$ & 39,010 & $20.1(19.4-20.8)$ \\
\hline Never married/live with a partner & 46,471 & $14.1(13.5-14.6)$ & 46,012 & $14.4(13.9-15.0)$ \\
\hline \multicolumn{5}{|l|}{ Employment status } \\
\hline Employed & 138,721 & $8.9(8.6-9.2)$ & 137,869 & $8.6(8.4-8.9)$ \\
\hline Unemployed & 11,858 & $22.7(21.5-24.0)$ & 11,713 & $21.9(20.6-23.2)$ \\
\hline Not in labor force & 50,844 & $28.7(28.0-29.4)$ & 50,127 & $20.2(19.6-20.8)$ \\
\hline \multicolumn{5}{|l|}{ Federal poverty level, $\%$} \\
\hline$<100$ & 23,075 & $31.0(30.0-32.0)$ & 22,759 & $23.6(22.7-24.6)$ \\
\hline $100-400$ & 73,013 & $16.6(16.1-17.1)$ & 72,367 & $13.6(13.1-14.0)$ \\
\hline$>400$ & 82,601 & $6.0(5.7-6.3)$ & 82,259 & $6.5(6.2-6.9)$ \\
\hline Unknown & 22,734 & $15.8(15.1-16.6)$ & 22,324 & $13.1(12.3-13.8)$ \\
\hline
\end{tabular}

Abbreviations: $\mathrm{Cl}$, confidence interval; FMD, frequent mental distress; GED, general education diploma.

${ }^{a}$ Including diabetes, coronary heart disease, stroke, current asthma, arthritis, cancer, chronic obstructive pulmonary disease, history of depression, kidney disease, and disability. Disability was defined as respondents who were limited in any way in any activities because of physical, mental, or emotional problems, or who had any health problem that required them to use special equipment (eg, cane, wheelchair, special bed, special telephone).

The opinions expressed by authors contributing to this journal do not necessarily reflect the opinions of the U.S. Department of Health and Human Services, the Public Health Service, the Centers for Disease Control and Prevention, or the authors' affiliated institutions. 
(continued)

Table 1. Crude Prevalence of Self-Perceived Poor/Fair Health and FMD Among Working-Aged Adults in 42 States and the District of Columbia, by Sociodemographic Characteristics, Health-Related Behaviors, and Chronic Conditions and Disability, Behavioral Risk Factor Surveillance System, 2014

\begin{tabular}{|c|c|c|c|c|}
\hline \multirow[b]{2}{*}{ Characteristic } & \multicolumn{2}{|c|}{ Poor/Fair Health } & \multicolumn{2}{|c|}{ FMD } \\
\hline & No. & $\%(95 \% \mathrm{Cl})$ & No. & $\%(95 \% \mathrm{Cl})$ \\
\hline \multicolumn{5}{|l|}{ Current smoking } \\
\hline Yes & 37,329 & $24.9(24.1-25.6)$ & 36,834 & $23.3(22.6-24.1)$ \\
\hline No & 164,094 & $12.2(12.0-12.5)$ & 162,875 & $9.6(9.4-9.9)$ \\
\hline \multicolumn{5}{|c|}{ Leisure-time exercise } \\
\hline Yes & 161,356 & $10.8(10.6-11.1)$ & 160,202 & $10.4(10.1-10.6)$ \\
\hline No & 40,067 & $30.4(29.6-31.2)$ & 39,507 & $20.6(19.9-21.3)$ \\
\hline \multicolumn{5}{|c|}{ Body mass index, $\mathrm{kg} / \mathrm{m}^{2}$} \\
\hline$<25.0$ & 68,283 & $10.1(9.7-10.5)$ & 67,700 & $11.3(10.9-11.8)$ \\
\hline $25.0-29.9$ & 70,543 & $12.2(11.8-12.6)$ & 69,973 & $10.8(10.3-11.2)$ \\
\hline$\geq 30.0$ & 62,597 & $23.7(23.1-24.3)$ & 62,036 & $15.8(15.3-16.3)$ \\
\hline \multicolumn{5}{|c|}{ Number of chronic conditions and disability ${ }^{a}$} \\
\hline 0 & 92,513 & $4.4(4.2-4.7)$ & 92,021 & $4.8(4.6-5.1)$ \\
\hline 1 & 49,088 & $10.6(10.1-11.2)$ & 48,688 & $11.4(10.9-12.0)$ \\
\hline 2 & 27,245 & $24.5(23.6-25.5)$ & 26,951 & $20.4(19.5-21.3)$ \\
\hline$\geq 3$ & 32,577 & $54.5(53.6-55.4)$ & 32,049 & $37.2(36.3-38.2)$ \\
\hline
\end{tabular}

Abbreviations: $\mathrm{Cl}$, confidence interval; FMD, frequent mental distress; GED, general education diploma.

${ }^{a}$ Including diabetes, coronary heart disease, stroke, current asthma, arthritis, cancer, chronic obstructive pulmonary disease, history of depression, kidney disease, and disability. Disability was defined as respondents who were limited in any way in any activities because of physical, mental, or emotional problems, or who had any health problem that required them to use special equipment (eg, cane, wheelchair, special bed, special telephone).

The opinions expressed by authors contributing to this journal do not necessarily reflect the opinions of the U.S. Department of Health and Human Services, the Public Health Service, the Centers for Disease Control and Prevention, or the authors' affiliated institutions. 
Table 2. Crude and Age-Adjusted Prevalence and APRs for Self-Perceived Poor/Fair Health and FMD Among Adults Aged 18 to 64 Years in 42 States and the District of Columbia, by Insurance Status and Type of Insurance, Behavioral Risk Factor Surveillance System, 2014

\begin{tabular}{|c|c|c|c|c|}
\hline \multirow[b]{2}{*}{ Insurance Status } & \multirow[b]{2}{*}{ No. } & \multicolumn{2}{|c|}{$\%$ (95\% Confidence Interval } & \multirow[b]{2}{*}{$\operatorname{APR}^{b}(\% 95 \mathrm{Cl})$} \\
\hline & & Crude & Age Adjusted $^{a}$ & \\
\hline \multicolumn{5}{|c|}{ Poor/Fair Health } \\
\hline \multicolumn{5}{|c|}{ Insurance coverage during the past 12 months } \\
\hline Adequately insured & 118,446 & $9.7(9.4-10.0)$ & $8.9(8.6-9.2)$ & 1.00 \\
\hline Underinsured & 59,921 & $22.7(22.2-23.3)$ & $21.8(21.3-22.4)$ & $1.39(1.33-1.44)$ \\
\hline Never insured & 14,794 & $22.9(21.8-24.1)$ & $23.4(22.3-24.6)$ & $1.59(1.50-1.68)$ \\
\hline \multicolumn{5}{|l|}{ Insurance type } \\
\hline Employer-based insurance & 116,080 & $8.3(8.0-8.6)$ & $7.8(7.5-8.1)$ & 1.00 \\
\hline Self-purchased plan & 19,732 & $9.8(9.1-10.5)$ & $9.3(8.6-10.1)$ & $1.00(0.93-1.08)$ \\
\hline Medicaid or Medicare & 26,045 & $39.2(38.1-40.2)$ & $36.5(35.5-37.6)$ & $1.28(1.22-1.36)$ \\
\hline Other public insurance & 11,107 & $18.8(17.6-20.1)$ & $17.3(16.1-18.7)$ & $1.13(1.06-1.21)$ \\
\hline Not currently insured & 21,368 & $21.4(20.5-22.4)$ & $22.5(21.6-23.4)$ & $1.48(1.39-1.57)$ \\
\hline \multicolumn{5}{|c|}{ FMD } \\
\hline \multicolumn{5}{|c|}{ Insurance coverage during the past 12 months } \\
\hline Adequately insured & 117,630 & $8.3(8.1-8.7)$ & $8.5(8.1-8.8)$ & 1.00 \\
\hline Underinsured & 59,296 & $18.8(18.3-19.4)$ & $18.8(18.2-19.3)$ & $1.38(1.31-1.44)$ \\
\hline Never insured & 14,625 & $16.7(15.7-17.8)$ & $16.8(15.8-17.8)$ & $1.38(1.29-1.48)$ \\
\hline \multicolumn{5}{|l|}{ Insurance type } \\
\hline Employer-based insurance & 115,424 & $8.2(8.0-8.5)$ & $8.5(8.2-8.9)$ & 1.00 \\
\hline Self-purchased plan & 19,606 & $9.3(8.6-10.1)$ & $8.8(8.1-9.6)$ & $0.95(0.87-1.04)$ \\
\hline Medicaid or Medicare & 25,568 & $27.4(26.4-28.4)$ & $27.2(26.1-28.2)$ & $1.15(1.08-1.23)$ \\
\hline Other public insurance ${ }^{c}$ & 10,976 & $15.6(14.5-16.8)$ & $15.8(14.6-17.2)$ & $1.15(1.05-1.25)$ \\
\hline Not currently insured & 21,123 & $16.7(15.9-17.6)$ & $16.8(16.0-17.7)$ & $1.24(1.16-1.33)$ \\
\hline
\end{tabular}

Abbreviation: APR, adjusted prevalence ratio; $\mathrm{Cl}$, confidence interval; $\mathrm{FMD}$, frequent mental distress.

age adjusted (age groups of 18-25 y, 26-44 y, and 45-64 y were used) to the 2000 projected US population.

${ }^{\mathrm{b}}$ Adjusted for age, sex, race/ethnicity, education level, marital status, employment status, federal poverty level, current smoking, leisure-time physical activity, body mass index, and the number of self-reported, physician-diagnosed chronic conditions (including diabetes, coronary heart disease, stroke, current asthma, arthritis, cancer, chronic obstructive pulmonary disease, history of depression, kidney disease, and disability). Disability was defined as respondents who were limited in any way in any activities because of physical, mental, or emotional problems, or who had any health problem that required them to use special equipment, such as a cane, wheelchair, special bed, or special telephone.

${ }^{c}$ Includes TRICARE (formerly CHAMPUS), Veterans Affairs, or military plan; Alaska Native, Indian Health Service, Tribal Health Services, or some other source. 